\title{
A Química e o mundo de amanhã
}

Este artigo é baseado numa comunicação apresentada por Linus C. Pauling durante a Cerimónia de Recepção da Medalha Priestley, no Encontro de Primavera da American Chemical Society (ACS) em St. Louis. Mantendo-se ainda em actividade com 84 anos de idade, Pauling é director do Linus Pauling Institute of Science and Medicine, Palo Alto, Califórnia, onde continua a sua pesquisa cientifica. Linus Pauling introduziu a Mecânica Quântica na Química e contribuiu de forma notável para o avanço do conhecimento sobre a estrutura das moléculas e a natureza das ligaçōes químicas, nomeadamente para os compostos complexos e macromoleculares. A medalha Priestley, que constitui o mais alto prémio da ACS, reconhece a sua contribuição nestas e noutras áreas, e é o mais recente duma longa lista de prèmios que Pauling recebeu, e que inclui o Prémio Nobel da Quimica (recebido em 1954 pelo seu trabalho sobre ligaçðes quimicas) e o Prémio Nobel da Paz (recebido em 1962 pela sua defesa da paz mundial e do desarmamento).

Trinta anos atrás, dei uma conferência no Encontro Nacional da American Chemical Society com o titulo “A. Química e o Mundo de Hoje”. Profer. esta conferência na qualidade de novo presidente da f.CS. Comecei então por perguntar "O que poderei dizer sob o título "A Quimica e o Mundo de Hoje"? A minha resposta a esta pergunta é que posso dizer qualquer coisa, discutir qualquer faceta da vida moderna, porque cada aspecto do mundo de hoje - incluindo politica e relações internacionais - é afectado pela quimica."

Nesta minha conferência sublinhei que durante os anos da Segunda Guerra Mundial começámos a aplicar na prática a nossa reserva de novas descobertas fundamentais e que desde então se tornou claro que, ainda que todos os cientistas dêem a sua contribuição para o progresso científico, a vida moderna é de facto baseada na ciência fundamental, na pesquisa pura, e que a natureza do mundo de hoje tem sido determinada, e que a natureza do mundo de amanhã será determinada, pelo trabalho, e sobretudo pelas ideias, dum pequeno número de pessoas - os "impractical scientists" 1, principalmente professores universitários, que procuram ampliar o nosso corpo de conhecimentos em todos os sentidos, em vez de resolver alguns problemas práticos que obviamente carecem de solução. Disse na altura que não estava a minimizar a importância da investigação de desenvolvimento e da aplicação industrial de novas descobertas, mas estava sim a apontar que a direcção na qual o progresso ocorre é de facto determinada pelas descobertas fundamentais que são feitas e que, portanto, é o progresso da ciência pura que determina qual a natureza do mundo na geração seguinte.

Em 1945 as Comissões que prepararam o Relatório Bush propuseram a constituição de uma Fundação Nacional da Ciência (National Science Fundation, NSF),e que fundos federais que poderiam ascender a

\footnotetext{
${ }^{1}$ Entre aspas no texto original.
}

250 milhões de dólares por ano em poucos anos, seriam apropriados para o financiamento da investigação científica fundamental. Mais de dois anos passaram sem que fossem tomadas medidas sobre esta proposta e eu pressionei o Congresso no sentido de constituir a NSF e de lhe atribuir os fundos apropriados. Também pressionei no sentido de contrabalançar este esforço federal através da constituição de um outro fundo para financiar a investigação fundamental, este proveniente das indústrias dos EUA, de modo que a investigação não fosse dominada pelo governo federal. A NSF surgiu pouco depois, mas não foi possivel à American Chemical Society conseguir a organização pelas grandes corporações industriais dum fundo comparável ao do governo federal para financiar a investigação fundamental; a consequência foi que o governo federal é actualmente a força dominante no apoio à investigação fundamental.

Do mesmo modo que a natureza do mundo de 1945 tinha em grande parte sido determinada pelas descobertas feitas por quimicos e outros cientistas, podemos ver claramente que as modificações que ocorreram na natureza do mundo nos últimos 35 anos foram também determinadas por descobertas cientificas e sua aplicação aos problemas práticos. A natureza do mundo de amanhã dependerá do que nós fizermos - do que nós fizermos como químicos, e do que nós e os nossos concidadãos fizermos como seres humanos. Os dois factores que deter'ninarão a natureza do mundo de amanhã são o conhecimento que possuirmos e as decisð̃es que tomarmos acerca do modo de utilizar esse conhecimento.

Sinto-me particularmente feliz por ter a oportunidade de proferir esta conferência Priestley. É para mim uma grande satisfação saber que os três quimicos que me nomearam para esta medalha disseram que eu tinha alguma semelhança com Priestley, porque quer os interesses de Priestley quer os meus próprios incluiram não só a ciência como também os princípios morais. Posso no entanto sublinhar que há uma diferença entre nós. No que me diz respeito, foi a ciência que surgiu em primeiro lugar; mais tarde, já há várias décadas formulei um princípio ético básico que, em minha opinião, resulta de uma linha de pensamento essencialmente cientifica. Priestley, pelo contrário, começou por ser um moralista.

Ainda que Priestley seja hoje lembrado principalmente como cientista, a sua vida foi de facto na sua maior parte dedicada à análise social, política, religiosa

- "Chemistry and tomorrow's world", L. Pauling, chem. Eng. News, 62, 54 (1984). Tradução de J.P. Conde, com autorização do autor e da American Chemical Society (copyright 1984).

a) Linus Pauling Institute of Science and Medicine, 440 Page Mill Road Palo Alto, Califórnia 94306. 
e filosófica, à escrita e à educação. Ele sentiu que os problemas suscitados por estes dominios poderiam ser abordados de modo mais efectivo através da obtenção de conhecimentos adicionais sobre a natureza do mundo. Quando em 1758, com 25 anos de idade, se mudou para Nantwich (Inglaterra), onde era pastor duma congregação não-conformista, abriu uma escola. Da Encyclopaedia Britannica, nona edição, 1885, cito a seguinte passagem, "Sempre dando o melhor da sua inteligência a tudo o que empreendia, variava as suas liçōes elementares com instrução em filosofia natural, ilustrada por experiências, para as quais podia agora dispôr dos instrumentos necessários"'.

Os seus estudos tinham sido até esta altura inteiramente literários, filosóficos e teológicos. Neles, no entanto, patenteava as caracteristicas fundamentais dum cientista - honestidade, racionalidade, liberdade relativamente a preconceitos e dogmas. Estas caracteristicas parecem ter sido inatas nele, e foram alimentadas pela sua entrada numa academia não conformista com a idade de 19 anos. Com 17 anos de idade, era estritamente ortodoxo e "ansiava realizar as experiências que ele supunha serem necessárias para a conversão religiosa. A sua principal dificuldade era não conseguir arrepender-se da transgressão de Adão, uma dificuldade que nunca conseguiu ultrapassar. $O$ peso desta impossibilidade forçou a sua mente cândida a chegar à conclusão de que deveria haver um erro algures, e começou a duvidar se estaria tão comprometido na culpa de Adão como the tinha sido ensinado".

No seu trabalho cientifico, Priestley explorou uma nova técnica, que abriu um novo campo da química a técnica do manuseamento de gases recolhendo-os pneumaticamente sobre água ou mercúrio num recipiente. Esta inovação pode ser comparada à introdução, já no século $X X$, da cristalografia de raios $X$ na quimica estrutural, ou da cromatografia na química analitica. Utilizando esta técnica, Priestley descobriu dez novos gases e contribuiu significativamente para o desenvolvimento da quimica moderna. Um dos biógrafos de Priestley, Gibbs, perguntou: "Como foi que, neste campo difícil e obscuro (da existência e natureza de diferentes tipos de gases), ele foi capaz de fazer avanços que tinham escapado a tantos homens de ciência? O próprio Priestley justificava isto pelo seu hábito de investigar os cantos misteriosos e obscuros, e de seguir uma intuição sem ideias preconcebidas fosse qual fosse a conclusão final. Foi praticamente o único de entre os cientistas da sua época a ser suficientemente honesto para atribuir pelo menos parte do seu sucesso ao entusiasmo e a um profundo gosto pela aventura. Observar um pedaço de hortelã numa jarra de vidro virada de pernas para o ar sobre um recipiente de água ou um rato numa caneca de cerveja invertida, era sempre para ele um acontecimento com múltiplas consequências. Mantinha-se cuidadosamente à procura de qualquer indicação que pudesse levar a meios para aumentar a riqueza e felicidade da humanidade. Por detrás destas atitudes, estava a sua convicção de que o rápido progresso do conhecimento seria "o meio de, sob a vigilância de Deus, pôr fin a toda a autoridade usurpada e indesejável nos assuntos da religião, assim como nos da ciência".

Fomos testemunhas dos rápidos progressos da ciência durante as últimas décadas. Neste momento, os compostos organometálicos, especialmente os dos metais de transição, são objecto de grande interesse da parte dos químicos e é provàul que as descobertas que estão a ser feitas neste domínio tenham um pronunciado efeito no mundo do futuro. Algumas décadas atrás uma nova ciência, a biologia molecular, desenvolveu-se como resultado do interesse dos quimicos estruturais na natureza dos organismos vivos. As consequências deste desenvolvimento já se sentem actualmente; basta pensarmos no esforço que está a ser feito na engenharia genética e em campos afins.

$\mathrm{O}$ que é mais importante, em relação à ciência e ao mundo do futuro, é a existência de armas nucleares, baseadas nos processos de fissão e fusão nucleares que foram descobertos por físicos e químicos nucleares há cerca de meio século. A questão fundamental que actualmente se coloca é a de saber se o mundo terá ou não futuro - se haverá um amanhã. É em relação a esta pergunta que os quimicos têm a sua obrigação primordial enquanto cidadãos.

Muitos de nós lembram-se dum exceptional quimico-físico, George Kistiakowsky, que morreu há um ano e meio com 82 anos de idade. Tinha sido oficial no exército branco da Rússia com 21 anos e traballıador manual nos Balcãs, tendo estudado depois quimica em Berlim antes de vir para os EUA. Trabalhei com ele na divisão de explosivos da Comissão de Investigação da Defesa Nacional, e em 1944 ele tornou-se chefe da divisão de explosivos em Los Alamos. De 1959 a 1961 foi conselheiro científico do Presidente Eisenhower. Durante os 12 últimos anos da sua vida dedicou-se ao trabalho em favor da paz mundial. O seu último artigo, publicado em 2 de Dezembro de 1982, no Bulletin of the Atomic Scientist, foi sobre a paz mundial. Nele descrevia o desenvolvimento das armas nucleares, e escrevia: "os Soviéticos, claro, mantiveram-se a par de nós a maior parte dos aspectos. E eis-nos actualmente possuidores de 50000 ogivas nucleares: mais do que suficiente para produzir um holocausto que não só destruiria a civilização industrial mas que provavelmente teria efeitos ambientais generalizados sobre a Terra dos quais a recuperação não seria de modo nenhum garantida.

"Como alguém que tentou alterar esta tendência através de uma acção sobre as instâncias oficiais quer, do interior delas quer, durante os últimos doze anos, a partir do seu exterior, não posso deixar de vos aconseIhar como minha opinião derradeira, que esqueçam essas instâncias.

"Não nos resta muito tempo antes da destruição do mundo.

"Preocupem-se antes em organizar um movimento de massas sem precedentes em favor da paz.

"A ameaça de aniquilação não tem precedentes".

Deste modo, como disse Kisty, temos de levar a cabo uma acção sem precedentes para salvar o mundo.

Nós, como químicos, podemos contribuir para desenvolver um mundo melhor. O nosso dever principal neste momento é trabalhar para educar os nossos concidadãos. Estamos face à ameaça sem precedentes de extinção da raça humana numa guerra nuclear, e devemos unir-nos para levar a cabo acções sem precedentes para impedir esta aniquilação e para atingir o objectivo da abolição da guerra. É nosso dever contribuir para que o mundo de amanhã exista. 